\title{
EFEITOS DO TREINAMENTO RESISTIDO NA FORÇA MUSCULAR EM IDOSOS COM SARCOPENIA: ESTUDO DE REVISÃO LITERÁRIA
}

\author{
https://dx.doi.org/10.48097/2674-8673.2021n5p08
}

\author{
Jorge Cavalcanti Machado de Souza ${ }^{1}$ \\ Manuella Moraes Monteiro Barbosa Barros ${ }^{2}$
}

\section{RESUMO}

Com o aumento da longevidade o número de idosos vem crescendo exponencialmente, colaborando para o aparecimento de doenças como a sarcopenia, uma doença que gera perda de massa muscular, força e função. O maior problema do envelhecimento não é o processo em si, mas a falta de atividade que o acompanha, podendo comprometer a capacidade de realizar atividades diárias. Um fator fundamental para um envelhecimento saudável é a prática de atividade física regular. Este estudo teve como objetivo relatar os efeitos dos exercícios resistidos na força muscular nos idosos com sarcopenia. Foi possível concluir que o tratamento fisioterapêutico na sarcopenia é fundamental e extremamente necessário, atuando na prevenção, promoção e na reabilitação, melhorando a qualidade de vida, que é um fator determinante para uma longevidade no idoso.

Palavras-chave: Idosos. Exercícios resistidos. Sarcopenia.

Data de submissão: $23 / 03 / 2021$

Data de aprovação: 30/04/2021

\begin{abstract}
With the increase in longevity the number of elderly people has been growing exponentially, contributing to the appearance of diseases such as sarcopenia, a disease that generates loss of muscle mass, strength and function. The biggest problem with aging is not the process itself, but the lack of activity that accompanies it, which can compromise the ability to perform daily activities. A fundamental factor for healthy aging is the practice of regular physical activity. This study aimed to report the effects of resistance exercises on muscle strength in the elderly with sarcopenia. It was possible to conclude that physiotherapeutic treatment in sarcopenia is fundamental and extremely necessary, acting on prevention, promotion and rehabilitation, improving quality of life, which is a determining factor for longevity in the elderly.
\end{abstract}

Keywords: Elderlies. Resistance exercises. Sarcopenia.

\section{INTRODUÇÃO}

A população mundial apresenta um número crescente de idosos. É certo que isto é consequência do processo evolutivo e tecnológico para a melhoria da qualidade de vida da

\footnotetext{
${ }^{1}$ Discente do curso de Fisioterapia da Faculdade Metropolitana da Grande Recife.

E-mail: jorgecmachado57@gmail.com

2 Docente orientadora do curso de Fisioterapia da Faculdade Metropolitana da Grande Recife.

E-mail: manuella@metropolitana.edu.br
} 
população. Ocorreu um maior incentivo científico nos processos de compreensão das enfermidades crônicas degenerativas, maior preocupação na percepção saúde-doença, programas governamentais de incentivo ao aumento do acesso aos serviços de saúde e elevação da expectativa de vida. Quando existe a prática regular do exercício resistido ocorre uma melhora no controle das entidades patológicas. Observa-se desde 1940, no Brasil, um incremento do número de idosos sobre os adultos jovens. Na década seguinte, as taxas foram na ordem de $3 \%$ e nos últimos dez anos de 2000 , houve elevação na ordem de $3,4 \%$. Um novo fenômeno foi desenhado com uma população de idosos crescendo na ordem de 126,3\% enquanto dos adultos foi de 55,3\% entre 1980 e 2005. (CARDOSO et al., 2012; GORDON et al, 2012; INOUYE, PEDRAZZANI, PAVARINI, 2008).

Com as mudanças na dinâmica demográfica da população idosa no Brasil e no mundo este nicho de pessoas tem se mostrado crescente. Nas últimas seis décadas houve um acréscimo de 15 milhões de indivíduos idosos no país, passando de 4\% para $9 \%$ da população brasileira. Provavelmente em 2025 teremos um aumento de mais 33 milhões, tornando o Brasil o sexto país com maior índice percentual populacional de idosos no mundo. Assim como a elevação do número de idosos também há um crescimento de algumas doenças e comorbidades relacionadas ao processo natural de envelhecimento, dentre estes, pode-se destacar a sarcopenia. (PÍCOLI et al 2011; PARAHYBA, 2006; FREITAS, 2006; SILVA et al, 2006).

Novas demandas de saúde estão ocorrendo devido às mudanças sócio-demográficas da população mundial, adicionando-se novas demandas de saúde. O envelhecimento é um dos fatores que apontam mudanças epidemiológicas no perfil das doenças, induzindo a maior incidência de doenças crônicas degenerativas e suas complicações. Pode-se apresentar a síndrome da fragilidade e a sarcopenia, tendo em vista os malefícios que exercem na funcionalidade e na qualidade de vida dos idosos. (VIANA et al., 2013).

Guedes et al (2008), relatam que com a idade avançada algumas modificações fisiológicas ocorrem, como a diminuição da força muscular, diminuição da frequência cardíaca máxima, diminuição da massa muscular, diminuição da coordenação motora, diminuição da flexibilidade, diminuição da propriocepção, diminuição do metabolismo basal e aumento da gordura corporal.

Segundo Mazo et al (2007), o declínio do sistema locomotor, causado pelo processo da senescência e/ou senilidade, são causas de incapacidade e falta de equilíbrio que aumentam os riscos de quedas, podendo levar muitas vezes à incapacidade de manter-se equilibrado, prejudicando funções básicas do cotidiano. O período da velhice é muito associado ao 
declínio das funções corporais e mentais, o que desestimula o idoso a procurar uma prática que reduza os impactos do envelhecimento. Assim, tornam-se menos ativos à medida que aumentam de idade, contribuindo para a redução de sua independência social. (GIELEN et al., 2015).

Conforme Garcia (2011), estima-se uma redução de 20 a 40 por cento na força muscular e na mobilidade funcional em idosos de 70 a 80 anos. Essa perda de massa e força muscular definida como sarcopenia é inevitável com o envelhecimento e é uma das alterações fisiológicas mais importantes que ocorrem em adultos mais velhos. A redução da força muscular e da potência muscular e a consequente redução da mobilidade funcional em idosos se devem ao declínio da massa muscular associado ao envelhecimento.

O sedentarismo, a ociosidade e a facilidade na comunicação são os maiores incentivadores do estilo de vida não saudável. A prevenção desse estilo de vida deve ser observada a fundo, pois viver desta forma nos impede de realizar práticas corporais, as quais são fundamentais para nossa qualidade de vida e para um envelhecimento saudável (MINISTÉRIO DA SAÚDE, 2006). Atualmente, a procura por exercícios resistidos em idosos é consequência de indicação médica ou pela busca de uma qualidade de vida mais abundante. Ao compreender a importância de ter uma vida ativa, as pessoas tornam-se adeptas a essa prática.

De acordo com Nicastro \& Peterson (2011) e Waters (2010), devido à magnitude dos desfechos adversos da independência do idoso, qualidade de vida e aumento da carga sobre os sistemas de saúde, diversas estratégias possíveis para prevenir e /ou tratar a sarcopenia foram desenvolvidas ao longo dos anos. Apesar dos recursos nutricionais, hormonais e farmacológicos, o treinamento resistido é citado como um dos melhores caminhos para o tratamento da sarcopenia. As adaptações morfológicas e funcionais ao exercício resistido foram bem descritas na literatura e o treinamento resistido progressivo deve melhorar as alterações neuromusculares, força muscular, massa muscular e desempenho em idosos.

Segundo Cruz-Jentoft et al (2011), exercícios de resistência consistem em realizar contrações dinâmicas ou estáticas contra a resistência, como levantar pesos, usar máquinas de resistência ou faixas elásticas. Esses exercícios de resistência aumentarão o conteúdo de mioglobina muscular entre $75 \%$ e $80 \%$, o que favorece o armazenamento de oxigênio, aumenta o número e o tamanho das mitocôndrias e aumenta as enzimas oxidativas. Todas essas mudanças que ocorrem nos músculos, juntamente com as adaptações no sistema de transporte de oxigênio, produzem um funcionamento mais intenso do sistema oxidativo e uma melhora na capacidade de resistência. Além disso, esse tipo de exercício não apenas aumenta 
a massa e a força muscular, mas também melhora outros aspectos como equilíbrio, capacidade aeróbica, flexibilidade e outras limitações funcionais. Esse treinamento é importante em idosos, mas, para tirar proveito dele, é necessário levar em consideração a relação entre intensidade e duração.

De acordo com o Colégio Americano de Medicina Esportiva (2009), esses exercícios devem ser realizados de 2 a 3 dias por semana, em 1 a 3 séries de 8 a 12 repetições cada, incluindo os 8 a 10 principais grupos musculares, com uma intensidade de $70 \%$ a $80 \%$ da potência máxima que pode ser realizada com esse grupo muscular e com um minuto de descanso entre as séries.

Nos estudos avaliados por Miyazaki et al. (2016), o exercício resistido melhora significativamente a força muscular e a hipertrofia, sendo atribuído ao exercício resistido a capacidade de ganho de força.

Diante do exposto, o objetivo deste estudo foi pesquisar, através de uma revisão literária, o efeito da sarcopenia, ocasionado pelo sedentarismo que ele implica na funcionalidade dos membros superiores e inferiores, na massa corporal e força muscular dos idosos.

\section{METODOLOGIA}

Trata-se de uma revisão descritiva de literatura cujo objetivo geral foi verificar o impacto da sarcopenia e o efeito dos exercícios resistidos na funcionalidade de idosos $(\geq 60$ anos). Foram pesquisados artigos escritos e disponíveis na plataforma do site da Biblioteca Virtual de Saúde nos idiomas português e inglês, que estivessem indexados nas bases de dados "Medical Literature Analysis and Retrieval System Online" (MEDLINE), Scientific Eletronic Library Online (SCIELO) e Literatura Latino-Americana e do Caribe em Ciências da Saúde (LILACS), usando como descritores: "Idoso", "Sarcopenia" e "Exercícios Resistido" (“Aged", "Sarcopenia", "Exercise").

No rastreamento das publicações foi utilizado o operador booleano "AND", de modo a combinar os termos descritores acima citados. Foram encontrados 92 artigos no MEDLINE, 13 artigos no SCIELO e não foi encontrado nenhum no LILACS, totalizando 105 estudos.

As buscas dos artigos foram realizadas no período de março a maio do ano de 2020, ressaltando que não ocorreu restrição temporal. Os idiomas pesquisados foram inglês e português e foi usado o filtro de Ensaio Clínico para busca dos artigos. Os critérios de inclusão concentram-se nos artigos científicos de sarcopenia em idosos ( $\geq 60$ anos), exercícios 
resistidos, definição terapêutica e fisioterápica. Foram considerados critérios de exclusão a sarcopenia decorrente de patologias autoimunes, doenças metabólicas, cardiológicas, pulmonares, neurológicas e cognitivas.

\section{RESULTADOS}

A seleção dos estudos foi realizada inicialmente com a leitura do título e resumo dos trabalhos, sendo selecionados os que abordassem o objetivo geral dessa revisão descritiva de literatura. Dos 105 estudos encontrados apenas 17 foram lidos na íntegra. Destes, 08 foram contemplados para explanação dos dados, sendo submetidos a uma análise qualitativa e integral com aprofundamento de seus conteúdos. As etapas da revisão dos estudos estão na Figura 1 e os dados dos estudos selecionados estão contidas na tabela 1.

Figura 1. Fluxograma das etapas do estudo baseado no modelo Prisma 2009
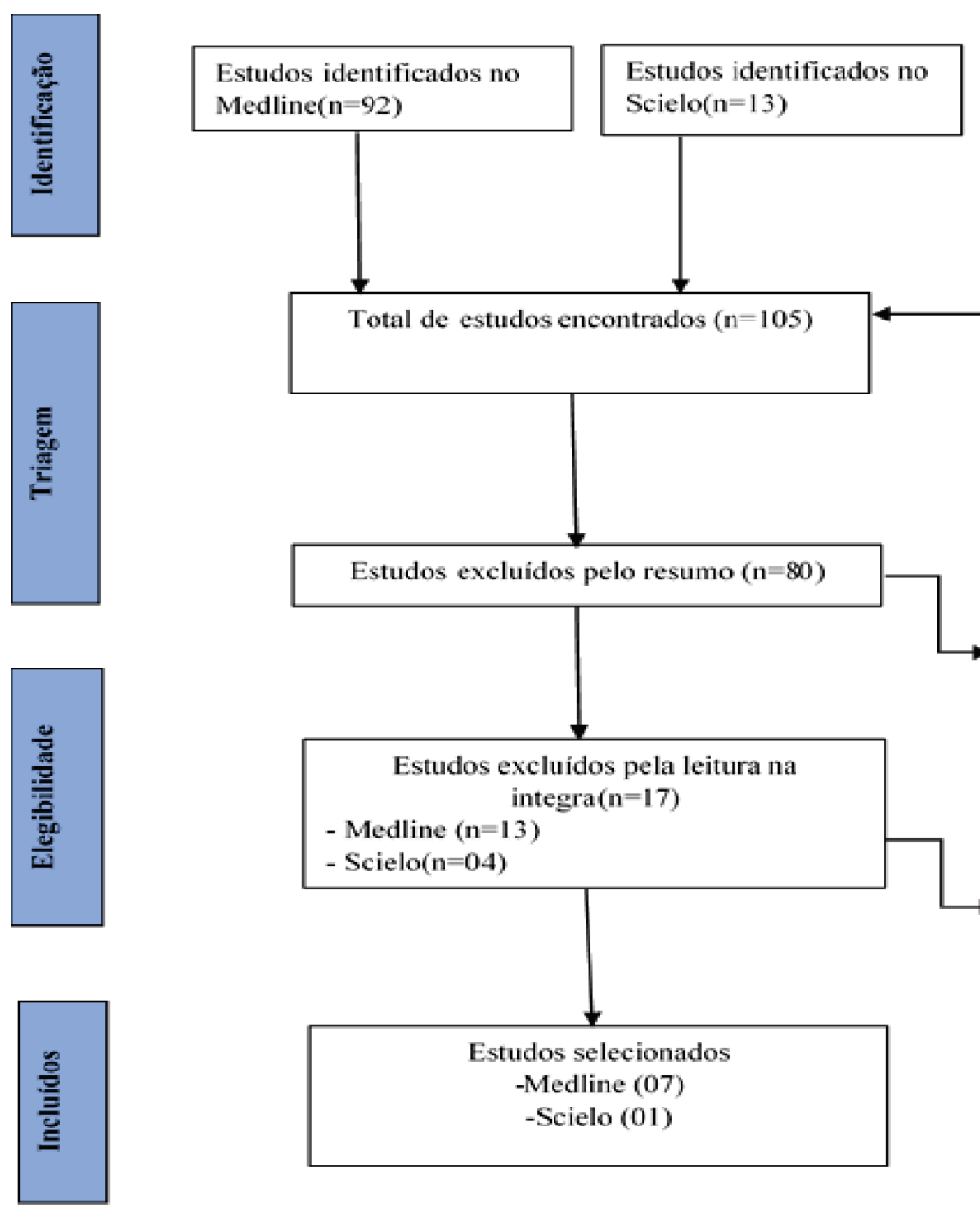

Estudos identificados no Lilacs $(\mathbf{n}=0)$

Estudos excluídos por motivo:

doenças correlacionadas

- Medline $(\mathrm{n}=13)$

- Scielo $(\mathrm{n}=06)$

Nầ está de acordo com o

objetivo:

- Medline (59)

-Scielo ( 02$)$

Estudos excluidos por motivo:

Fora do contexto

- Medline $(n=13)$

- Scielo $(n=4)$

Fonte: os autores 
Tabela 1. Características dos estudos elegíveis para revisão.

\begin{tabular}{|c|c|c|c|c|c|}
\hline Autores/ Ano & $\begin{array}{l}\text { Título do } \\
\text { Estudo }\end{array}$ & $\begin{array}{l}\text { Tipo do } \\
\text { Estudo }\end{array}$ & Objetivos & Resultado & Conclusão \\
\hline $\begin{array}{l}\text { PIASTRA et al. } \\
2018\end{array}$ & $\begin{array}{l}\text { Effects of } \\
\text { Two Types of } \\
\text { 9-Month } \\
\text { Adapted } \\
\text { Physical } \\
\text { Activity } \\
\text { Program on } \\
\text { Muscle Mass, } \\
\text { Muscle } \\
\text { Strength, and } \\
\text { Balance in } \\
\text { Moderate } \\
\text { Sarcopenic } \\
\text { Older Women }\end{array}$ & $\begin{array}{l}\text { Ensaio } \\
\text { clínico } \\
\text { randomiza } \\
\text { do. }\end{array}$ & $\begin{array}{l}\text { Avaliar os efeitos } \\
\text { de dois tipos de } \\
\text { programa ras de } \\
\text { atividade física } \\
\text { adaptada (APA) de } \\
9 \text { meses, baseados } \\
\text { em treinamento de } \\
\text { reforço muscular e } \\
\text { treinamento sobre } \\
\text { postural muscular, } \\
\text { massa muscular e } \\
\text { força mático } \\
\text { equilíbrio estáto } \\
\text { em idosos } \\
\text { sarcopênicos } \\
\text { moderados } \\
\text { mulheres. }\end{array}$ & $\begin{array}{l}\text { O estudo } \\
\text { realizado em } \\
\text { mulheres } \\
\text { idosas } \\
\text { sarcopênicas } \\
\text { moderadas, } \\
\text { demonstrou } \\
\text { que o grupo } \\
\text { RESISTANCE } \\
\text { apresentou } \\
\text { melhoras } \\
\text { significativas } \\
\text { na massa e } \\
\text { função } \\
\text { muscular após } \\
\text { o programa de } \\
\text { reforço } \\
\text { muscular } \\
\text { proposto, } \\
\text { enquanto que } \\
\text { não foram } \\
\text { encontradas } \\
\text { diferenças } \\
\text { significativas } \\
\text { no grupo } \\
\text { POSTURAL, } \\
\text { após o } \\
\text { treinamento } \\
\text { postural } \\
\text { adotado. }\end{array}$ & $\begin{array}{l}\text { Os presentes } \\
\text { achados mostram a } \\
\text { eficácia de um } \\
\text { programa de reforço } \\
\text { muscular na massa e } \\
\text { função muscular, } \\
\text { bem como nos } \\
\text { parâmetros de } \\
\text { equilíbrio estático } \\
\text { em mulheres idosas } \\
\text { sarcopênicas. Esse } \\
\text { tipo de abordagem } \\
\text { pode reduzir fatores } \\
\text { de risco de queda, } \\
\text { como sarcopenia e } \\
\text { comprometimento } \\
\text { do equilíbrio. }\end{array}$ \\
\hline $\begin{array}{l}\text { YAMADA et al. } \\
2019\end{array}$ & $\begin{array}{l}\text { Synergistic } \\
\text { effect of } \\
\text { bodyweight } \\
\text { resistance } \\
\text { exercise and } \\
\text { protein } \\
\text { supplementati } \\
\text { on on skeletal } \\
\text { muscle in } \\
\text { sarcopenic or } \\
\text { dynapenic } \\
\text { older adults. }\end{array}$ & $\begin{array}{l}\text { Estudo } \\
\text { controlado } \\
\text { randomiza } \\
\text { do de } \\
\text { quatro } \\
\text { braços. }\end{array}$ & $\begin{array}{l}\begin{array}{l}\text { Investigar os efeitos } \\
\text { do exercício } \\
\text { resistido ao peso } \\
\text { corporal }\end{array} \text { e } \\
\text { suplementação de } \\
\text { proteínas e vitamina } \\
\text { D no músculo } \\
\text { esquelético r em } \\
\text { idosos sarcopênicos } \\
\text { e dinapênicos. }\end{array}$ & $\begin{array}{l}\text { Os } \\
\text { participantes } \\
\text { do grupo } \\
\text { combinado } \\
\text { tiveram uma } \\
\text { melhora } \\
\text { significativame } \\
\text { nte maior na } \\
\text { intensidade do } \\
\text { eco do reto } \\
\text { femoral e no } \\
\text { torque de } \\
\text { extensão do } \\
\text { joelho do que } \\
\text { os dos outros } \\
\text { grupos. Além } \\
\text { disso, } \\
\text { programa } \\
\text { combinado } \\
\text { aumentou a } \\
\text { massa } \\
\text { muscular } \\
\text { apendicular em } \\
\text { idosos } \\
\text { sarcopênicos, }\end{array}$ & $\begin{array}{lr}\text { Um programa } \\
\text { combinado de } 12 \\
\text { semanas re } \\
\text { exercícios resistidos } \\
\text { ao peso corporal e } \\
\text { suplementação de } \\
\text { proteínas e vitamina } \\
\text { D é eficaz para } \\
\text { melhorar r a } \\
\text { qualidade muscular } \\
\text { e a força muscular } \\
\text { em idosos com } \\
\text { sarcopenia } \\
\text { dinapenia. }\end{array}$ \\
\hline
\end{tabular}


mas não em

idosos com

baixa função

física e massa

muscular

normal.

\begin{tabular}{|c|c|c|c|c|c|}
\hline $\begin{array}{l}\text { Hiroyasu } \\
\text { Mori e Yasunob } \\
\text { u Tokuda } \\
2018\end{array}$ & $\begin{array}{l}\text { Effect of } \\
\text { whey protein } \\
\text { supplementati } \\
\text { on after } \\
\text { resistance } \\
\text { exercise on } \\
\text { the muscle } \\
\text { mass and } \\
\text { physical } \\
\text { function of } \\
\text { healthy older } \\
\text { women: A } \\
\text { randomized } \\
\text { controlled } \\
\text { trial }\end{array}$ & $\begin{array}{l}\text { Estudo } \\
\text { controlado } \\
\text { randomiza } \\
\text { do. }\end{array}$ & $\begin{array}{l}\text { Avaliar a eficácia } \\
\text { de um programa de } \\
24 \text { semanas de } \\
\text { suplementação } \\
\text { nutricional com } \\
\text { proteína de soro de } \\
\text { leite, ingerida após } \\
\text { exercícios, no } \\
\text { aumento da massa } \\
\text { muscular e da } \\
\text { função física entre } \\
\text { mulheres japonesas } \\
\text { saudáveis. }\end{array}$ & $\begin{array}{l}\text { O aumento pré } \\
\text { e pós- } \\
\text { intervenção no } \\
\text { índice de } \\
\text { massa } \\
\text { muscular } \\
\text { esquelética foi } \\
\text { maior no grupo } \\
\text { de apenas } \\
\text { exercício do } \\
\text { que no grupo } \\
\text { somente } \\
\text { suplementação } \\
\text { de proteína e } \\
\text { significativame } \\
\text { nte maior no } \\
\text { grupo e } \\
\text { exercício } \\
\text { suplementação } \\
\text { protéica do que } \\
\text { nos apenas de } \\
\text { exercício ou } \\
\text { apenas de } \\
\text { suplementação } \\
\text { protéica. }\end{array}$ & $\begin{array}{l}\text { O efeito positivo da } \\
\text { suplementação de } \\
\text { proteína de soro de } \\
\text { leite, ingerida após } \\
\text { o exercício resistido } \\
\text { foi o aumento da } \\
\text { massa muscular e } \\
\text { força entre mulheres } \\
\text { japonesas idosas. }\end{array}$ \\
\hline $\begin{array}{l}\text { Chun-De Liao } \\
\text { et al. } \\
2017\end{array}$ & $\begin{array}{l}\text { Effects of } \\
\text { elastic } \\
\text { resistance } \\
\text { exercise on } \\
\text { body } \\
\text { composition } \\
\text { and physical } \\
\text { capacity in } \\
\text { older women } \\
\text { with } \\
\text { sarcopenic } \\
\text { obesity A } \\
\text { CONSORT- } \\
\text { compliant } \\
\text { prospective } \\
\text { randomized } \\
\text { controlled } \\
\text { trial }\end{array}$ & $\begin{array}{l}\text { Estudo } \\
\text { prospectiv } \\
\text { o e } \\
\text { randomiza } \\
\text { do, com } \\
\text { uma } \\
\text { análise de } \\
\text { intenção de } \\
\text { tratar. }\end{array}$ & $\begin{array}{l}\text { Identificar a eficácia } \\
\text { clínica do } \\
\text { treinamento } \\
\text { resistido elástico em } \\
\text { pacientes com } \\
\text { obesidade } \\
\text { sarcopênica. }\end{array}$ & $\begin{array}{l}\text { No pós-teste, } \\
\text { foi observada } \\
\text { uma diferença } \\
\text { significativa } \\
\text { entre os grupos } \\
\text { em massa livre } \\
\text { de gordura, } \\
\text { qualidade } \\
\text { muscular e } \\
\text { capacidade } \\
\text { física; e uma } \\
\text { correlação } \\
\text { significativa } \\
\text { foi encontrada } \\
\text { entre a da } \\
\text { alteração da maga } \\
\text { massa dernas a } \\
\text { das perna } \\
\text { velocidade da } \\
\text { marcha. Após } \\
\text { 12 semanas de } \\
\text { intervenção } \\
\text { elástica do } \\
\text { treinamento } \\
\text { resistido } \\
\text { elástico, } \\
\text { Grupo } \\
\text { Experimental } \\
\text { teve }\end{array}$ & $\begin{array}{l}\text { Os presentes dados } \\
\text { sugerem que o } \\
\text { exercício resistido } \\
\text { elástico exerceu } \\
\text { benefícios na } \\
\text { composição } \\
\text { corporal, qualidade } \\
\text { corporal e função } \\
\text { física em pacientes } \\
\text { com obesidade } \\
\text { sarcopênica. } \\
\text { Exercícios regulares } \\
\text { que incorporam o } \\
\text { treinamento } \\
\text { resistido devem ser } \\
\text { usados para atenuar } \\
\text { a perda de massa } \\
\text { muscular e prevenir } \\
\text { dificuldades físicas } \\
\text { em obesos com } \\
\text { sarcopenia. }\end{array}$ \\
\hline
\end{tabular}


significativame

nte menos

pacientes

exibindo

sarcopenia em

relação

ao

Grupo

Controle.

$\begin{array}{lll}\text { ZDZIEBLIK et } & \text { Collagen } & \text { Estudo } \\ \text { al. } & \text { Peptide } & \text { randomiza } \\ 2015 & \text { Supplementat do, duplo- } \\ & \text { ion in cego, } \\ & \text { Combination controlado } \\ & \text { With } & \text { por } \\ & \text { Resistance placebo. } \\ & \text { Training } & \\ & \text { Improves } \\ & \text { Body } & \\ & \text { Composition } \\ & \text { and Increases } \\ & \text { Muscle } \\ & \text { Strength in } \\ & \text { Elderly } \\ & \text { Sarcopenic } \\ & \text { Men: } \\ & \text { Randomised A } \\ & \text { Controlled } \\ & \text { Trial }\end{array}$

Avaliar a influência

da suplementação

protéica

exercício

pós-

peptídeos

colágeno versus pla

cebo na massa

muscular e na

função muscular

após treinamento

resistido em idosos

com sarcopenia.
O presente acordo com investigações anteriores, mostrando que o exercício resistido

melhora força, a massa sarcopenia. Compar livre de ados com o placebo, gordura, a os indivíduos do coordenação e grupo suplementado o controle com colágeno postural no mostraram um envelheciment aumento maior na o da massa livre de população.

Os peptídeos de colágeno aumentaram ainda mais os benefícios do treinamento resistido de três meses em indivíduos idosos gordura e força estudo está de muscular e redução maior na massa gorda.
Os resultados indicaram um aumento significativo da massa livre de gordura em todos os grupos $\mathrm{e}$ alterações na força muscular, sem diferenças entre grupos. resistido é uma maneira eficaz de aumentar a massa muscular e a força, independentemente da suplementação. Doses mais altas de alimentos ricos em proteínas são recomendadas para promover ganhos de executar exercícios.
O treinamento massa muscular ao

$\begin{array}{ll}\text { Mathieu } & \text { The Effect of } \\ \text { Maltais, Joëlle } & \text { Resistance } \\ \boldsymbol{P} & \text { Training and } \\ \text { Ladouceur, Isab } & \text { Different } \\ \text { elle J Dionne. } & \text { Sources of } \\ 2016 & \text { Postexercise } \\ & \text { Protein } \\ & \text { Supplementat } \\ & \text { ion on } \\ & \text { Muscle Mass } \\ & \text { and Physical } \\ & \text { Capacity in } \\ & \text { Sarcopenic } \\ & \text { Elderly Men }\end{array}$

Estudo
randomiza
do, duplo-
cego,
controlado

nvestigar os efeitos de um programa de exercícios resistidos de 16 semanas combinado com o consumo aminoácidos essenciais suficientes de pó comercial ou leite em pó sobre a massa muscular, capacidade física e funcional em homens idosos sarcopênicos.

$\begin{array}{lll}\text { CUNHA et al. } & \text { The Effects Estudo } \\ 2017 & \text { of Resistance randomiza } \\ & \text { Training do } \\ & \text { Volume on controlado. } \\ & \text { Osteosarcope } \\ & \text { nic Obesity in } \\ & \text { Older Women }\end{array}$

Analisar os efeitos

do treinamento resistido realizado com 1 ou 3 séries por exercício nos parâmetros síndrome obesidade osteossarcopênica em mulheres idosas. 


\begin{tabular}{|c|c|c|c|c|c|}
\hline & & & & $\begin{array}{l}\text { pontuação em } \\
\text { força. }\end{array}$ & $\begin{array}{l}\text { induzindo melhorias } \\
\text { em comparação a } \\
\text { uma série. }\end{array}$ \\
\hline $\begin{array}{l}\text { VIANA et al. } \\
2018\end{array}$ & $\begin{array}{l}\text { Effect of a } \\
\text { resistance } \\
\text { exercise } \\
\text { program for } \\
\text { sarcopenic } \\
\text { elderly } \\
\text { women: } \\
\text { quasi- } \\
\text { experimental } \\
\text { study }\end{array}$ & $\begin{array}{l}\text { Estudo } \\
\text { quasi- } \\
\text { experiment } \\
\text { al (pré-pós } \\
\text { intervençã } \\
\text { o). }\end{array}$ & $\begin{array}{l}\text { Avaliar o impacto } \\
\text { de um programa de } \\
\text { exercícios com } \\
\text { carga progressiva } \\
\text { no desempenho } \\
\text { muscular } \\
\text { funcional de idosas } \\
\text { sarcopênicas. }\end{array}$ & $\begin{array}{l}\text { Esses } \\
\text { resultados } \\
\text { demonstraram } \\
\text { que o } \\
\text { treinamento a } \\
75 \% \text { foi capaz } \\
\text { de recrutar } \\
\text { unidades } \\
\text { motoras e, } \\
\text { nesse caso, } \\
\text { provavelmente } \\
\text { fibras do tipo I, } \\
\text { que são mais } \\
\text { evidentes em } \\
\text { indivíduos } \\
\text { sarcopênicos. }\end{array}$ & $\begin{array}{l}\text { O Programa de } \\
\text { Treinamento de } \\
\text { Resistência } \\
\text { Progressiva é capaz } \\
\text { de combater as } \\
\text { perdas de massa } \\
\text { muscular, força e } \\
\text { desempenho físico } \\
\text { em idosos } \\
\text { sarcopênicos. }\end{array}$ \\
\hline
\end{tabular}

Fonte: os autores

\section{DISCUSSÃO}

O envelhecimento vem acompanhado da sarcopenia, mais conhecida como fraqueza muscular. Após certa idade, essa enfermidade é um grande fator causador de incapacidade em idosos. Com isso, vários estudos relatando as sequelas causadas por essa patologia podem ser encontrados, assim como tratamentos experimentais para amenizar seus efeitos.

Viana et al (2018), ao avaliarem os impactos de um programa de exercícios com carga progressiva em mulheres idosas sarcopênicas, notaram que após doze semanas de exercício, três vezes por semana, houve aumento de massa magra, aumento de força no quadríceps e melhorias tanto no desempenho funcional como muscular.

Piastra et al (2018), ao fazerem um estudo sobre os efeitos de um programa de nove meses de atividade física adaptada, utilizando dois exercícios (programa esse baseado em treino de reforço muscular e treino de postura em mulheres idosas e sarcopênicas), observaram que ao final do programa as mulheres obtiveram aumento de força e massa muscular, gerando, desse modo, efeitos positivos tanto em relação à sarcopenia quanto em relação à postura.

Cunha et al (2018) realizaram um estudo para analisar os efeitos da atividade física contra a obesidade osteosarcopênica. Para isso, participaram do estudo sessenta e duas mulheres idosas que integravam um programa de doze semanas de treino de resistência três vezes por semana. As idosas foram divididas em 3 grupos: um grupo controle (GC), um grupo que fez uma série por dia de exercícios (G1), e um grupo que fez três séries de exercícios 
(G3). Ao final do estudo foi comprovado que apesar de o tempo de exercício de G3 ser pelo menos três vezes maior que G1, e G1 ser a alternativa mais atrativa entre as duas, quando se diz respeito ao tempo-eficiência, houve grandes mudanças entre o grupo G1 e G3 com relação à porcentagem de gordura corporal e força, com G3 possuindo os melhores resultados. Esse estudo comprovou que um período de treino de resistência de doze semanas é bastante efetivo para melhorar os fatores de risco da obesidade osteosarcopênica e que três séries geram melhores resultados que uma série de exercício durante esse período de tempo.

Ao conduzir um estudo em um centro de reabilitação, Liao et al (2017) analisaram os efeitos de um exercício de resistência elástica na composição corporal e na capacidade física em mulheres idosas portadoras de obesidade sarcopênica. Um total de quarenta e seis idosas, com idade média de sessenta e sete anos, foram divididas em dois grupos. Um grupo experimental (GE) treinou exercícios de resistência elástica por doze meses, e um grupo de controle (GC) não praticou o treino. Foram feitas medidas de composição corporal e qualidade muscular. Após o programa foram notadas diferenças entre a quantidade de massa livre de gordura entre os dois grupos, assim como a qualidade muscular e a capacidade física das idosas dos dois grupos. O número de idosas com sarcopenia diminuiu consideravelmente, assim como o número de idosas com dificuldades físicas. Além da melhoria física das idosas, esse estudo demonstrou que as mudanças na composição corporal estavam significativamente correlacionadas com a força muscular e a mobilidade física após o programa, mostrando que a perda de massa muscular está associada com o envelhecimento e o treinamento de resistência elástica é muito vantajoso para ganho de massa muscular e força em pessoas idosas.

Mori e Tokuda (2018) realizaram um estudo para observar os efeitos da ingestão da proteína whey na massa muscular e nas funções físicas de mulheres idosas saudáveis após a prática de treino de resistência. Esse estudo foi baseado em um programa de vinte e quatro semanas de suplementação nutricional ingerido após a prática de exercícios. Oitenta e uma mulheres com idade entre sessenta e cinco e oitenta anos foram divididas em três grupos: um grupo que praticou apenas exercícios de resistência (G1), outro que ingeriu apenas a suplementação (G2) e o terceiro que envolveu tanto a suplementação quanto o programa de exercícios de resistência (G3). Ao analisar os dados obtidos pré e pós-programa, pôde-se perceber que houve aumento no músculo esquelético dos grupos. O aumento foi significativamente maior em G1 do que em G2 e ainda maior em G3. Além disso, o grupo que relacionou a suplementação com exercícios obteve melhorias em firmeza, velocidade ao andar e maior ganho de massa muscular nos membros inferiores se comparado aos outros grupos, 
demonstrando que a ingestão de proteína whey após a prática de exercícios de resistência pode ser efetiva contra a sarcopenia em pessoas idosas.

Yamada et al (2018) analisaram os efeitos sinérgicos da prática de exercícios de resistência do peso corporal aliada à suplementação proteica com vitamina $\mathrm{D}$ no músculo esquelético em idosos sarcopênicos ou dinapênicos (perda de força e potência muscular causada pelo envelhecimento). Para esse estudo cento e doze idosos foram divididos em quatro grupos: um grupo de exercícios $(\mathrm{G} 1)$, um grupo de suplementação $(\mathrm{G} 2)$, um grupo controle (GC), e um grupo que combinou exercícios e suplementação (G3). O programa foi realizado em 12 semanas. O grupo G3 obteve resultados mais expressivos, aumentando a qualidade muscular e a força muscular de seus participantes dinapênicos e aumentando a massa muscular apendicular dos participantes sarcopênicos. Com isso, o estudo demonstrou que uma dieta de proteínas relacionada a exercícios físicos são de grande ajuda contra os efeitos da sarcopenia ou dinapenia, melhorando tanto a força quanto a massa muscular dos idosos. Porém, o autor considera esse estudo como tendo duas limitações que deveriam ser mencionadas: o tamanho das amostras que foram insuficientes nos subgrupos e alguns resultados que foram obtidos por ultrassonografia cujo método de medida é controverso. Mas, em geral os resultados obtidos foram satisfatórios.

Zdzieblik et al (2015) estudaram a influência do treino de resistência em combinação com uma suplementação de peptídeo colagenoso no aumento de força muscular em homens idosos sarcopênicos. Cinquenta e três idosos sarcopênicos com idade média de setenta e dois anos foram divididos em dois grupos e participaram de um programa de doze semanas de treinamento de resistência aliado à ingestão de peptídeo colagenoso (Grupo 1) ou sílica como placebo (Grupo 2). Massa magra, massa gorda e massa óssea foram medidas antes e depois do programa e a força isocinética do quadríceps foi medida durante a intervenção. Durante o estudo foi especulado que o momento em que se faz a suplementação, assim como a absorção cinética da proteína ingerida influenciam em sua eficácia. Rápida absorção e digestão cinética influenciam diretamente na hipertrofia muscular causada pelas proteínas. Ao final do estudo notou-se que todos os indivíduos mostraram maiores níveis de massa magra, massa óssea e força do quadríceps e níveis menores de massa gorda, sendo esses resultados ainda mais expressivos no grupo suplementado com peptídeo colagenoso, pois o colágeno é rico em glicina e arginina que são substâncias importantes para a síntese de creatina, cuja suplementação pode melhorar a massa e a função muscular no corpo humano. Esse estudo mostrou que uma dieta de peptídeo colagenoso combinado à prática de exercícios gera melhorias na composição corporal do idoso com sarcopenia. 
Dionne, Ladouceur e Maltais (2016) desenvolveram um estudo sobre o efeito do treino de resistência aliado à ingestão de proteínas pós-exercício na massa muscular e na capacidade física em homens sarcopênicos. Para esse estudo vinte e seis indivíduos foram divididos em três grupos que praticaram exercícios e ingeriram suplementos ricos em proteína pós-treino: proveniente de leite (Grupo 1), soja (Grupo 2) e leite de arroz (Grupo 3). Ao final de dezesseis semanas os dados demonstraram que houve aumento significativo na massa muscular e força nos participantes, demonstrando a importância de indivíduos com baixa massa muscular praticarem exercícios de resistência, além de indicar que pessoas idosas necessitam de um maior consumo de proteínas para obter um melhor impacto na força e massa muscular. Apesar dos ganhos gerais significativos o tratamento obteve baixa influência em relação à massa magra e ganhos na função física, pois os indivíduos eram sedentários e sarcopênicos.

Todos os estudos realizados com programas de exercícios físicos aliados à suplementação obtiveram resultados positivos contra os efeitos da sarcopenia, gerando melhora de vida para as pessoas idosas que participaram desses programas.

\section{CONCLUSÃO}

Através de uma revisão descritiva de literatura, foram revisados oito trabalhos cujos temas principais foram a sarcopenia em idosos com idade acima de sessenta anos e métodos para diminuição de seus efeitos e prevenção. Por meio dos trabalhos estudados pôdese observar que essa enfermidade chega com a idade, atingindo as pessoas idosas, causando fraqueza muscular e perda de massa muscular.

De acordo com os trabalhos inspecionados, alguns tratamentos aplicados foram bastante eficientes, em especial a prática de exercícios físicos três vezes por semana, trazendo diversos benefícios para a saúde do idoso, aumentando tanto a porcentagem de massa muscular quanto a força física e a diminuição da massa gorda. Diminuição da fraqueza, perda da dificuldade de andar, aumento de massa magra nos membros inferiores e melhor postura também foram pontos positivos obtidos pelas intervenções. Assim, esse tipo de tratamento se torna um meio de melhorar a qualidade de vida e as sequelas provenientes do envelhecimento e da sarcopenia.

Sendo assim, a participação efetiva dessa população em programas de exercícios físicos auxiliará na redução da sarcopenia e na consequente melhoria do desempenho nas AVD's e menores riscos à saúde. 


\section{REFERÊNCIAS}

CHODZKO-ZAJKO, W.; PROCTOR, D.; FIATARONE, S. M.; MINSON, C.; NIGG, C.; SALEM, G. Exercício e atividade física para idosos. Med Sci Sports Exerc. 2009; 41 (7): 1510-30.

CARDOSO, R. M. et al. Exercício resistido frente à sarcopenia: uma alternativa eficaz para a qualidade de vida do idoso. Revista Digital, Buenos Aires, v. 17, n. 169, 2012.

CRUZ-JENTOFT, A. J.; TRIANA, F. C.; GÓMEZ-CABRERA, M. C.; LÓPEZ-SOTO, A.; MASANÉS, F.; MARTÍN, P. M. A eclosão da sarcopenia: relatório preliminar do Observatório da Sarcopenia da Sociedade Espanhola de Geriatria e Gerontologia. Rev Esp Geriatr Gerontol. 2011; 46 (2): 100-10.

CUNHA, P. M. et al. The effects of resistance training volume on osteosarcopenic obesity in older women. Journal of sports sciences, v. 36, n. 14, p. 1564-1571, 2018.

FREITAS, E.V. Tratado de geriatria e gerontologia. 2. ed. Rio de Janeiro: Guanabara Koogan, 2006.

GARCIA, P. A.; DIAS, J. M. D.; DIAS, R. C.; SANTOS, P.; ZAMPA, C. C. Estudo da relação entre função muscular, mobilidade funcional e nível de atividade física em idosos residentes. Rev Bras Fisioter. 2011; 15 (1): 15-22.

GIELEN, E.; O’NEILL, T.; PYE, S. Endocrine determinants of incident sarcopenia inmiddleaged and elderly European men. Journal of Cachexia, Sarcopenia and Muscle 2015; 6: 242252.

GUEDES, D.; JUNIOR, T.; ROCHA, A. Treinamento personalizado em musculação. São Paulo: Phorte, 2008.

INOUYE, K.; SILVA, P..E.; IOST, P. S.; Octogenários e cuidadores: perfil sóciodemográfico e correlação da variável qualidade de vida. Texto \& Contexto Enfermagem, v. 17, n. 2, 2008.

LIAO, C. et al. Effects of elastic resistance exercise on body composition and physical capacity in older women with sarcopenic obesity: A CONSORT - compliant prospective randomized controlled trial. Medicine, v. 96, n. 23, 2017.

MALTAIS, M. L.; LADOUCEUR, J. P.; DIONNE, I. J. The effect of resistance training and different sources of postexercise protein supplementation on muscle mass and physical capacity in sarcopenic elderly men. Journal of strength and conditioning research, v. 30, $\mathrm{n}$. 6, p. 1680-1687, 2016.

MINISTÉRIO DA SAÚDE. Envelhecimento e saúde da pessoa idosa. Secretaria de Atenção à Saúde. Departamento de Atenção Básica. Brasília, 2006.

MIYAZAKI, R.; TAKESHIMA, T.; KOTANI, K. Exercise Intervention for Anti-Sarcopenia in Community-Dwelling Older People. J Clin Med Res., v. 8, n. 12, p. 848-853, 2016. 
MORI, H.; TOKUDA, Y. Effect of whey protein supplementation after resistance exercise on the muscle mass and physical function of healthy older women: a randomized controlled trial. Geriatrics \& gerontology international, v. 18, n. 9, p. 1398-1404, 2018.

NICASTRO, H., ZANCHI, N. E., LUZ, C. R.; LANCHA JR, A. H. Efeitos funcionais e morfológicos do exercício resistido na atrofia muscular esquelética induzida por desuso. Braz J Med Biol Res. 2011; 44 (11): 1070-9.

PARAHYBA, M. I. SIMÕES, C. C. S. A prevalência de incapacidade funcional em idosos no Brasil. Ciênc Saúde Coletiva. 2006;11(4):967-74.

PETERSON, M. D.; SEN, A.; GORDON, P. M. Influência do exercício resistido na massa corporal magra em adultos idosos: uma metanálise. Med Sci Sports Exerc. 2011; 43 (2): 249-58.

PIASTRA, G. et al. Effects of two types of 9-month adapted physical activity program on muscle mass, muscle strength, and balance in moderate sarcopenic older women. BioMed research international, v. 2018, 2018.

SILVA, T. A. A.; FRISOLI JR, A.; PINHEIRO, M. M.; SZEJNFELD, V. L. Sarcopenia associada ao envelhecimento: aspectos etiológicos e opções terapêuticas. Rev Bras Reumatol. v. 46, n.6, p.391-397, 2006.

VIANA, J. U. et al. Effect of a resistance exercise program for sarcopenic elderly women: quasi-experimental study. Fisioterapia em Movimento, v. 31, 2018.

WATERS, D. L.; BAUMGARTNER, R. N.; GARRY, P. J.; VELLAS, B. Vantagens de intervenções dietéticas, relacionadas a exercícios e terapêuticas para prevenir e tratar sarcopenia em pacientes adultos: uma atualização. Clin Interv Aging. 2010; 5: 259-70.

YAMADA, M. et al. Synergistic effect of bodyweight resistance exercise and protein supplementation on skeletal muscle in sarcopenic or dynapenic older adults. Geriatrics \& gerontology international, v. 19, n. 5, p. 429-437, 2019.

ZDZIEBLIK, Denise et al. Collagen peptide supplementation in combination with resistance training improves body composition and increases muscle strength in elderly sarcopenic men: a randomised controlled trial. British Journal of Nutrition, v. 114, n. 8, p. 1237-1245, 2015. 